\title{
Modeling, Simulation and a Comparative study between a Single-phase Switched Reluctance Machine (6x6) and a Three-phase Switched Reluctance Machine
}

\author{
Dias, R. J., Andrade, D.A., Cabral, L.G., Silveira, A.W.F.V., Silveira, A.F.V., Gomes, L.C., Bissochi, C. A \\ Laboratório de acionamentos elétricos, Depto. de Engenharia Elétrica, Universidade Federal de Uberlândia. \\ E-mails: renatojayme.ee@gmail.com, darizon@ufu.br
}

\begin{abstract}
The comparative study of electric machines has been in vogue due to the growing demand for electromechanical converters with maximum possible efficiency. In this scene, the switched reluctance machines have proven to be competitive. Comparative studies between these machines and the already established induction machines can be easily found in the scientific literature, but studies on various configurations of the switched reluctance machines are not as widespread. This paper shows the modeling, simulation and presents a comparative study of two Switched Reluctance Machines to a single phase $(6 \times 6)$ and three phase $(6 \times 4)$. Aspects of construction, drive and efficiency are discussed in order to find advantages and disadvantages to each of these machines.
\end{abstract}

\section{Key words}

Single phase Switched Reluctance Machine, Three phase Switched Reluctance Machine, comparison of efficiency.

\section{Introduction}

The interest in Switched Reluctance Machines (SRM) has getting a competitive market space. The industries are still in majority, induction machines; some synchronous machines that require a more rigorous maintenance due to the presence of brushes and rings; and fewer appear permanent magnet machines, losing competitiveness because of the high cost of magnets.

Several years ago, the obstacle to the interest in SRM was the high cost of power electronics, nowadays is not a problem due to the decrease in cost of microprocessors and semiconductor switches [1].

Because there are no windings, brushes and magnets on the rotor, the MRV in addition to having a simple structure and be more robust, have lower cost of manufacturing compared to other existing machines[1].Windings concentrated only in the stator, phases considered magnetically independent of one another, high torque per amp, high power density and high effiency are other advantages of this machines.

These advantages are leading more and more researchers to study on their application as electric motor cars, small domestic appliances, pumps, fans and others [2] [3] [4]. But there are also unfavorable characteristics for use as vibration and acoustic noise, yet several studies are already being taken to reduce these problems [5].

One study, not very rencent,[7] compares SRM with the indcuction machines.

The objective proposed in this paper is the comparasion of two SRM: a Single Phase Reluctance Motor (SPSRW) and a Three Phase Reluctance Motor
(TPSRW). The comparative study was carried out through simulations and experimental results.

\section{Structure of the machines}

A Switched Reluctance Machine (SRM) is composed of a laminated structure of double salience, simple, in which the coils are restricted only to the stator teeth. Moreover, in the case of this work, each coil of a pair of teeth opposite of the stator are a phase, as shown in Fig.1

This figure shows a $6 \times 4 \mathrm{SRW}$, in other words, a SRM with six stator poles and four poles in the rotor. Because each pair of poles in the stator form only one phase, this is a Three-Phase Switched Reluctance Machine to (TPSRM).

It also can be seen in Fig. 1 the connection in series of coils of each pair of teeth opposite to form of mentioned phase. Thus, the current that runs through these coils is the same. Fig. 1 shows the coils of only one phase, phase A, but this configuration is repeated for the other two phases. In this case, phase $\mathrm{A}$ is in its position of complete alignment, this position was chosen to be the reference in this work, ie, everytime the rotor is aligned with the stator at a certain phase, it is said that the rotor is in zero degree of that phase.

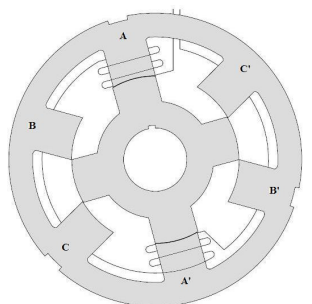

Fig.1 - Cross Section of a TPSRM, showing the winding of the phase A.

The Fig. 2 shows a 6x6 SRM. As can be seen, what distinguishes the two machines studied is only the number of teeth on the rotor and its drives. Again, each pair of teeth opposite in the stator was connected in series, but the energization of all coils will be held at the same time, no delay between pulses, hence this configuration of SRM, where the number of teeth rotor is equal to the number of stator teeth, is called a Singlephase Switched Reluctance Machine (SPSRM). The polarity of the windings of the other teeth are also represented in Fig. 2 . 


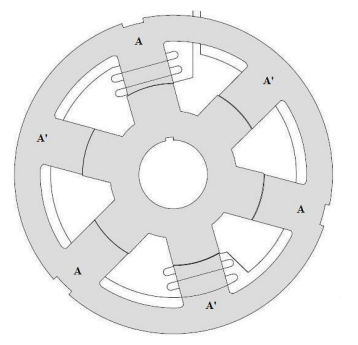

Fig.2 -Cross Section of a SPSRM, showing a part winding of the phase A.

\section{Principles of Drive}

For that each phase could be energized in the correct moment is necessary to know, every moment, the rotor position. For this, a positioning disc with optical sensors was placed on the machine shaft as shown in Fig.3.

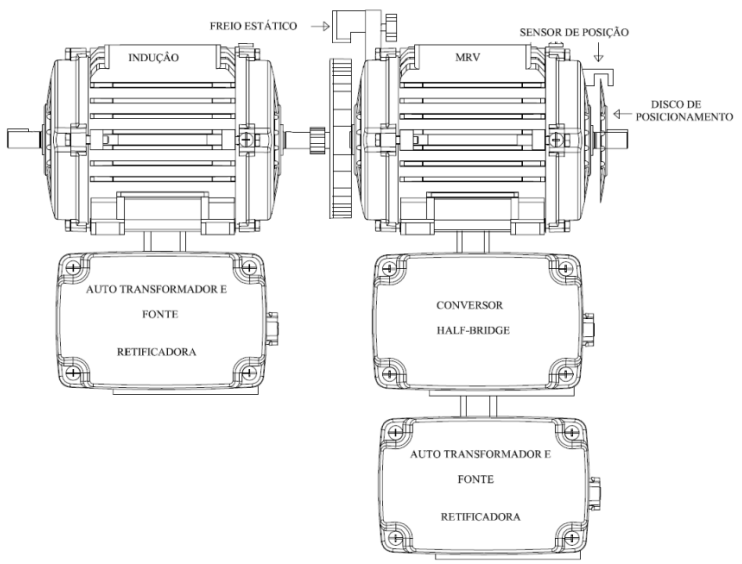

Fig.3 - Test bench showing SRM.

\section{A-Three Phase Switched Reluctance Machine}

To operate the TPSRM, was used a half-bridge converter. This converter was chosen to be the most applied to drive these machines [9].

Fig. 4 shows a three phase half-bridge converter. In this converter, the gate of each switch will be controlled by positioning sensor, insomuch that each phase will be energized when are completely disaligned (Fig. 5), at this point the switch $S_{1}$ and $S_{2}$ will be closed and the current coming from the source will flow through the coil Phase A.

This energizing will have a duration of 30 degrees, ie when is missing 15 degrees to the complete alignment this phase will be turned off, turning off the switches $S_{1}$ and $S_{2}$ (Fig. 6). At this point, the energy that was stored in the coil of phase A will be returned to the source, establishing a freewheel with the diodes $d_{1}, d_{2}$ and source.

The name Switched Reluctance Machine is due to the fact that his machine is always varying the reluctance. In the case of the $6 \times 4$ configuration the profile of reluctance is 90 degrees. As is known, the reluctance is inversely proportional to inductance. Figure 7 shows the inductance profile of a TPSRM

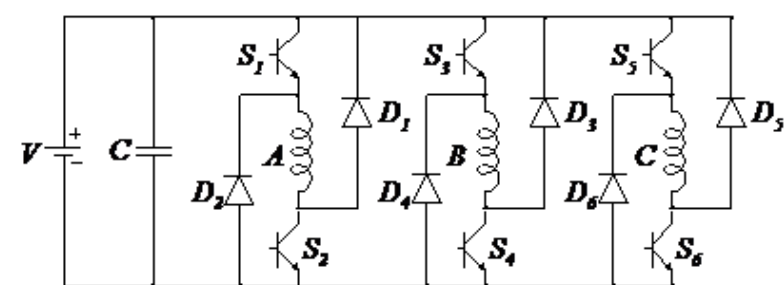

Fig.4 - Three Phase Half-Bridge converter.

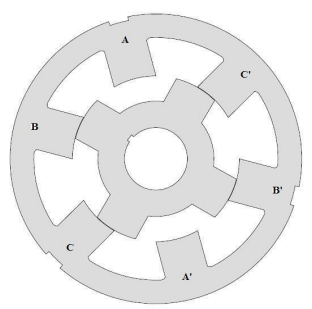

Fig.5 -Phase A completely disaligned in a TPSRM.

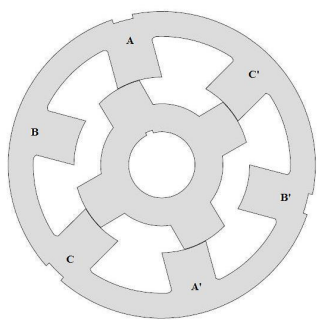

Fig.6 - Phase A missing 15 graus to aligned in a TPSRM.

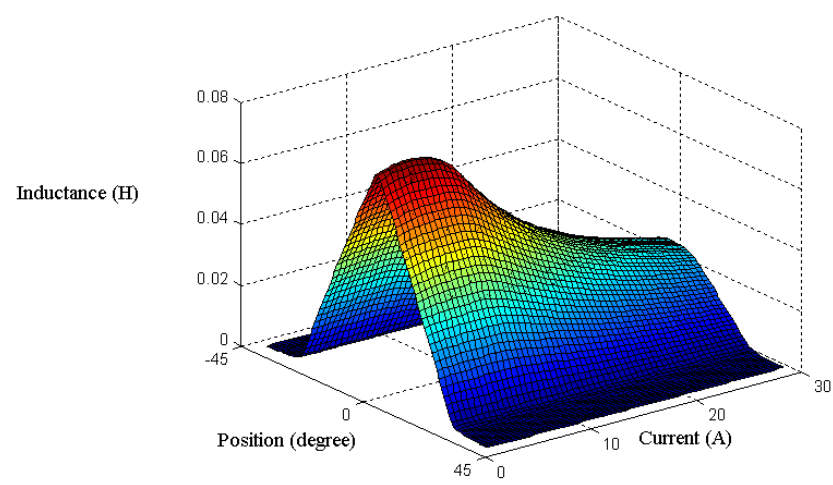

Fig.7 - Inductance profile of a TPSRM

\section{B-Single Phase Switched Reluctance Machine}

A Single Phase Switched Reluctance Machine (SPSRM) is a machine where, typically, the number of teeth on the rotor and stator are equal. Thus, there is no discrepancy between the profile of inductance of each stator tooth. Thus, these machines are seen as having only one phase. It is common to find projects with $2 \times 2,4 \times 4,6 \times 6$ and $8 \times 8$ poles on the stator and rotor, respectively [8]. Here, we will analyze the machine with $6 \times 6$ configuration.

To operate this machine, again used a half-bridge converter, however, in this case, it is necessary just a phase, as shown in Fig. 8 


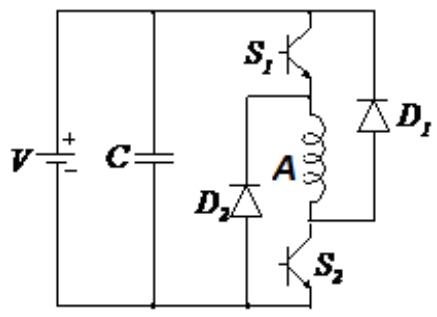

Fig. 8 - Single-phase half-bridge converter.

Thus, when the rotor is in complete disalignment, 30 degrees of alignment position, the machine will be energized (Fig. 9). At this point, switches $S_{1}$ and $S_{2}$ will be closed and the current coming from the source will flow through the coil of phase A.

This energizing will have a period of $15^{\circ}$, ie, when is missing $15^{\circ}$ for the complete alignment the phase will be turned off , turning off the switches $S_{1}$ and $S_{2}$ (Fig.10). At this point, the energy that was stored in the coil of phase A will be returned to the source. Establishing then a freewheel with diodes $\mathrm{d}_{1}, \mathrm{~d} 2$ and source.

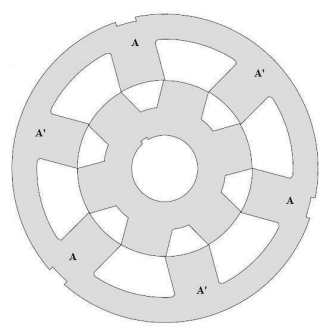

Fig.9 - Phase A completely disaligned in a SPSRM.

In the case of the $6 \times 6$ configuration the profile of reluctance have $60^{\circ}$. The Fig.11 shows the inductance profile of a SPSRM.

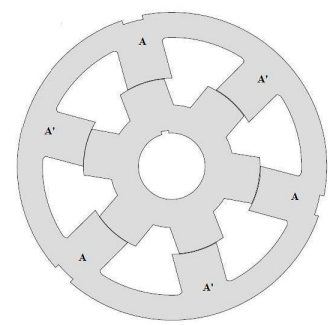

Fig. 10 - Phase A missing $5^{\circ}$ to aligned in a SPSRM.

\section{Mathematical Model}

In an inductor the flux linkage by the coil $(\lambda)$ is proportional to current $(i)$ that runs through the coil and its inductance $(L)$, have:

$$
v=R i+e
$$

Where:

$$
v=R i+\frac{\partial \lambda}{\partial t}
$$

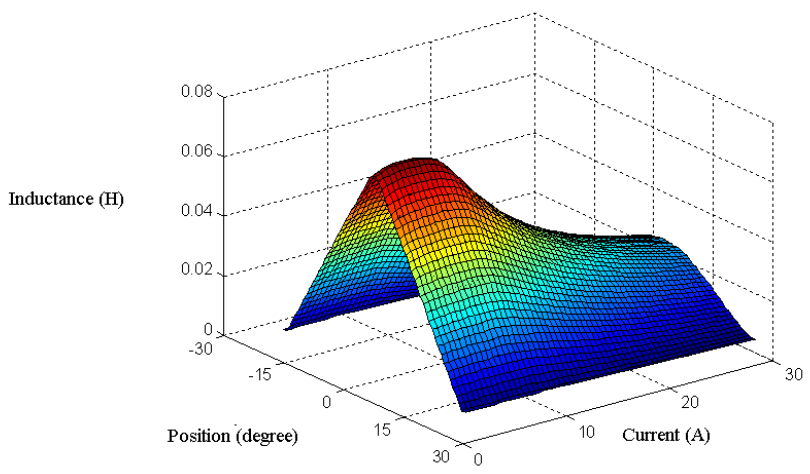

Fig.11 - Inductance profile of a SPSRM

In this way, the voltage at the terminal of each phase voltage have resistive in nature, due to resistance of the wires; and inductive, due to the coils of each tooth, so:

$$
v=R i+e
$$

Where:

$$
v=R i+\frac{\partial \lambda}{\partial t}
$$

As the flux linkage by the coils is proportional to the inductance and current the equation solution (4) involves a partial derivative, where firstly $L$ is considered constant and $i$ variable, and then $i$ is consired constant and $L$ variable. As $L$ is variable in relation to the rotor position and the time, replacing equation (1) in equation (4) and solving, have:

$$
v=R i+L \frac{\partial i}{\partial t}+i \frac{\partial L}{\partial \theta} \frac{d \theta}{d t}
$$

Conceptually, as the derivative of rotor angular position $(\theta)$ in relation to the time is the angular speed $(\omega)$ :

$$
v=R i+L \frac{\partial i}{\partial t}+i \omega \frac{\partial L}{\partial \theta}
$$

Equation (6) describes the SRM electrically, but for a complete modeling it is necessary other equation that glimpse the machine mechanically.For this just do the equalization the powers so that they are balanced. Thus the energy entering the system will generate a electromechanical torque $\left(T_{e m g}\right)$. In result of this input will be generated a mechanic torque $\left(T_{m e c}\right)$ on the system output. Moreover, should be considered that this machinhe should be able to win the rotational inertia of the speed variation $\left(J \frac{d \sigma}{d t}\right)$, and win the dynamic friction of the bearings $\left(D_{\bar{\sigma}}\right)$ [9].Thus:

$$
T_{e m g}=T_{m e c}+D_{\bar{\sigma}}+J \frac{d \varpi}{d t}
$$

Where:

$D$ is the coeficient of friction; $J$ is the moment of inertia. 
The electromechanical torque can be shown mathematically as :

$$
T_{\text {emg }}=\frac{1}{2} i^{2} \frac{d L}{d \theta}
$$

Therefore the equation (6) and the equation (7), together,describe in a complete ( electrically and mechanically) a single-phase SRM, so this work will consist on the comparison between a single-phase machine and a three-phase machine which should be represented in a matrix way so that all phases will be considered in the model then for the three-phase machine have:

$$
\begin{aligned}
& {\left[\begin{array}{c}
v_{1} \\
v_{2} \\
v_{3} \\
-T_{\text {mec }} \\
0
\end{array}\right]=\left[\begin{array}{ccccc}
R_{1} & 0 & 0 & 0 & 0 \\
0 & R_{2} & 0 & 0 & 0 \\
0 & 0 & R_{3} & 0 & 0 \\
-i_{1} r_{1} & -i_{2} r_{2} & -i_{3} r_{3} & D & 0 \\
0 & 0 & 0 & -1 & 0
\end{array}\right]\left[\begin{array}{c}
i_{1} \\
i_{2} \\
i_{3} \\
\varpi \\
\theta
\end{array}\right]+} \\
& {\left[\begin{array}{ccccc}
L_{1} & 0 & 0 & 0 & i_{1} \partial L_{1} / \partial \theta \\
0 & L_{2} & 0 & 0 & i_{2} \partial L_{2} \\
0 & 0 & L_{3} & 0 & i_{3} \\
0 & 0 & 0 & J & 0 \\
0 & 0 & 0 & 0 & 1
\end{array}\right]\left[\begin{array}{c}
\partial \theta \\
L_{3} \\
\dot{I}_{1} \\
\dot{I}_{2} \\
\dot{I}_{3} \\
\Phi \\
\dot{\theta}
\end{array}\right]}
\end{aligned}
$$

Where:

$r_{1}={ }_{1} \partial L_{1} / \partial \theta ; r_{2}={ }_{2} \partial L_{2} / \partial \theta ; r_{3}={ }_{3} \partial L_{3} / \partial \theta$

$\dot{I}_{1}$ is the derivative of the current of the phase 1 in time;

$\dot{I}_{2}$ is the derivative of the current of the phase 2 in time;

$\dot{I}_{3}$ is the derivative of the current of the phase 3 in time;

$\varpi$ is the angular speed variation in time;

$\dot{\theta}$ is the variation of rotor position in time.

\section{Simulations}

The simulation tools have facilitated the development of projects more accurate and cheaper in electric machines. Parameters that were previously impossible to consider, are now easily predicted in the design of these machines by simulation.

The simulations presented in this work were performed using MATLAB ${ }^{\circledR}$ SIMULINK.

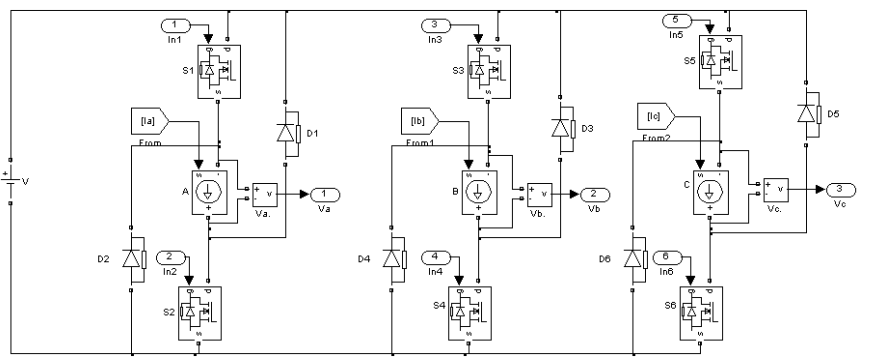

Fig 12. Three-phase half-bridge converter.

Thus, each machine was fought degree in degree, and its inductance was measured. The result can be seen in Fig.7 and Fig. 11.

\section{A.Simulation of a TPSRM}

In the simulation of a MRVT were used some tools ready of SIMULINK. The converter shown as electrical diagram in Figure 4 can be seen in Fig.12, but in SIMULINK.

In this converter was used controlled a current source by a signal in the simulation of the coils.

In addition to the converter is another block that simulates the mechanical and electrical behavior of the machine. This block can be seen in Figure 13. In this block were set as input, the voltage of the three phases and the load on the motor shaft. The load may have a quadratic behavior with respect to angular speed $(\omega)$, characteristic of typical loads such as fans for example or be a constant load.

The control signal from the current source of the converter is the phase current which is the output from block Fig. 13.

The Fig.13 is simply an S-function that solves the equation of state (9).

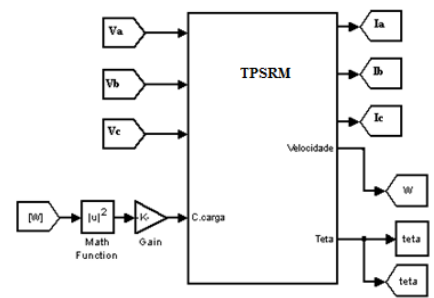

Fig.13 - Resolution of equation (9) in SIMULINK.

Input parameters of the Fig.13 are taken from the simulation of half-bridge converter in Fig.12.

\section{B. Simulation of a SPSRM}

The simulation of SPSRM, of course, was conducted the same way as was done for TPSRM.

Thus, Fig.14 shows the half-bridge converter which is electrically shown in Fig.8, but in the SIMULINK.

Again, the blocks of Fig 14 and Fig. 15 form a closed system because the output of Fig 15 (currents) are the input in Fig.14. And the output of Fig 14 (a voltage Va) is input in Fig 15.

Fig.15 is merely the solution of equations (7) and (8) of the mathematical model.

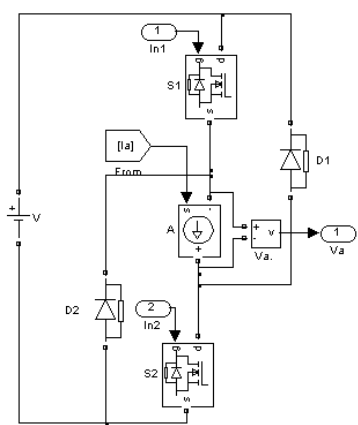

Fig.14 - Single-phase half-bridge converter. 


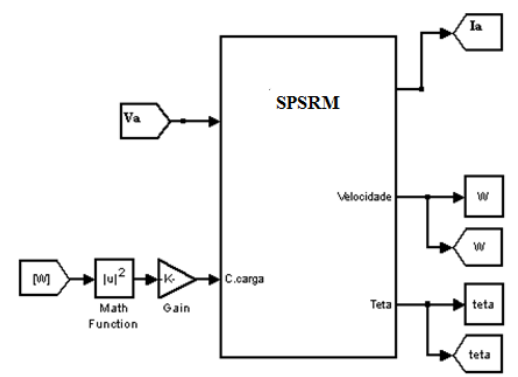

Fig.15 - Resolution of equation (7) and (8) in SIMULINK.

\section{Results of Simulations}

The simulations were done with machines fed with 311 $\mathrm{V}$ with rated load on their axes, with the aim of analyzing parameters such as wave form current on the phase, variations speed in machine and efficiency.

\section{A. Waveforms current on the phase}

The waveforms of the currents of the phases in the two machines can be seen in Fig.16 and Fig.17.

Fig. 16 shows the waveform of the current arising from the three phases of TPSRM.

Fig. 17 shows the waveform of current in a SPSRM.

These figures make it clear that the three-phase machine has a behavior more constant, because the phase are powered separately and there is always an active phase. In the SPSRM exists an interval where the machine is totally turned off, this would provide a more fickle behavior.

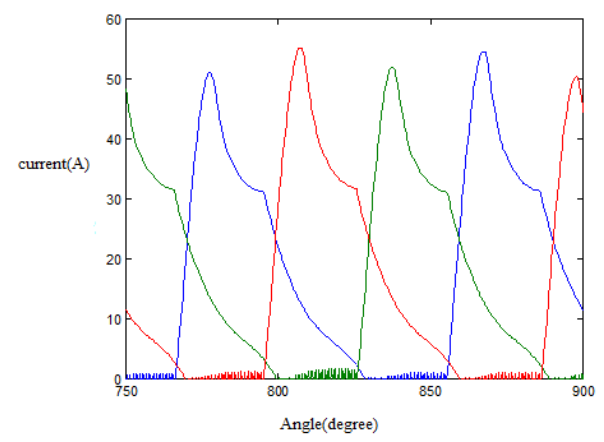

Fig.16 - Waveform of current in a TPSRM

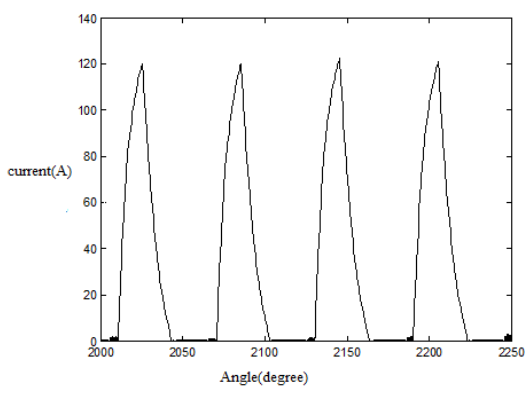

Fig.17 - Waveform of current in a SPRM.
The SRM are known to have problems in their oscillation parameters, including in the generated torque and in the speed.

The TPSRM showed a variation of speed sharp less than presented on the SPSRM. The range was of $127 \mathrm{rad} / \mathrm{s}$ to $119 \mathrm{rad} / \mathrm{s}$ with speed around $1200 \mathrm{rpm}$ desired for this machine.

However, SPSRM presented a disastrous change of speed, getting between $40 \mathrm{rad} / \mathrm{s}$ and $200 \mathrm{rad} / \mathrm{s}$. Since then this characteristic a huge disadvantage for this type of machine (6x6 MRVM $1 \mathrm{hp}$ ) when is driven in the way it was done in this work.

\section{Effiency of the machines}

Both machines showed good results regarding the efficiency item. TPSRM showed $91.5 \%$ and $81 \%$ SPSRM.

\section{Converters}

The single-phase converter of the SPSRM is simpler and cheaper than the converter of the MRVT by being composed of only one arm, and thus need only one switch to be operated.

\section{Experimental Results}

To perform comparative tests between the two configurations of SRM was mounted a bench containing two SRM, a three-phase induction machine (MIT) and a Half-bridge converter, as shown in fig.3. A MIT was used as a load. For this, a direct current was applied in phases in order to generate a fixed magnetic field and so when the SRM are operated and make the MIT turning, a power appears making that this works as a load.

In the first test the TPSRM was fed with a voltage of 200 $\mathrm{V}$ on the dc bus and the current values was incremented one to one starting from zero (empty machine) and go up to 7 A (Maximum load by MIT).

The graph in Fig. 18 shows the decrease of speed and increase of the power when the load on the shaft of the TPSRM increase.

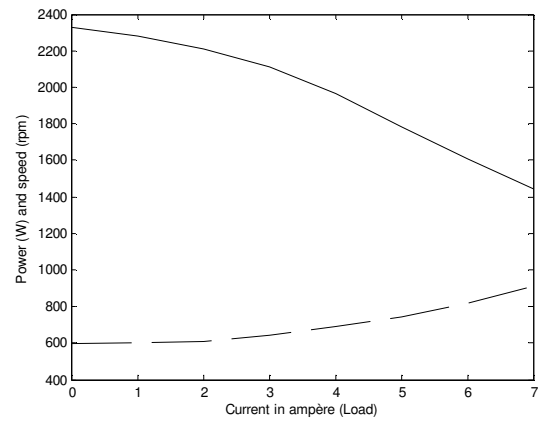

Fig.18 - Power (- - - ) and Speed (__

Then the same test was repeated for SPSRM, the result is shown in Fig.19.

\section{B. Speed of the machines}




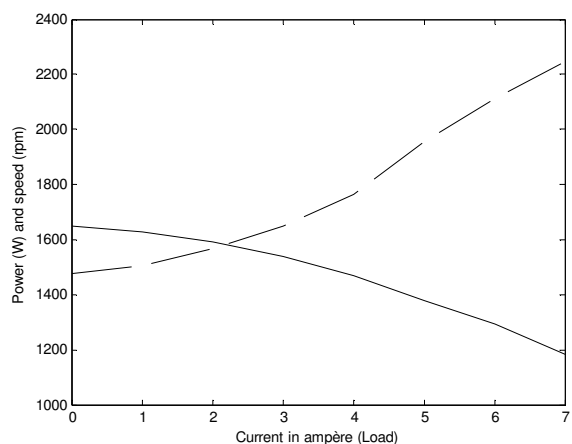

Fig. 19 - Power (- - - ) and Speed ( ) in a SPSRM.

These two figures (Fig. 18 and Fig.19) show that TPSRM when fed with constant voltage of $200 \mathrm{~V}$ always keep a faster speed than SPSRM, despite its derivative of speed in relation to the load to be greater. Moreover, the input power required by SPSRM is always greater than the TPSRM.

However, the analysis of input power was compromised in this test, because despite the magnetic power generated at MIT have relation to the current (x-axis of figures) it is also related to the speed of the machines which, as has been shown is different. So this first test reveals only the behavior of the machines for their speed when there is a increase in the load and voltage control in the dc bus.

Thus, takes necessary a second test in which speed in SRM were kept constant at $1200 \mathrm{rpm}$ (nominal speed) and the current MIT (load) was being added. The result is shown in Fig. 20.

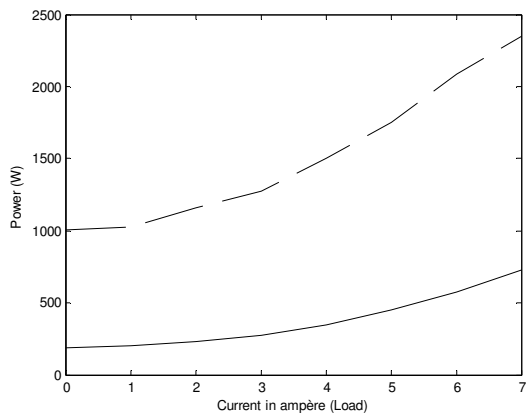

Fig.20 - Input Power in a SPSRM (- - -) and Input Power in a TPSRM ).

In Fig.20 shows that when subjected to the same load, the SPSRM requires a power input more than four times the input power required by a TPSRM. When these are operated the way it was done in this work.

\section{Conclusion}

Both machines have very similar aspects of construction, so there is no way to elect between the two that is better in this item.

TPSRM machine proved to be a more constant, with fewer variations in speed. This did not occur with SPSRM which was very swinging.

The converter SPSRM is simpler and inexpensive, requiring only two switch to operate it, but these switch must support peak currents greater than those that occur in TPSRM. In TPSRM is necessary to use six switchs. In the simulations, the TPSRM showed a yield of around 91.5\% and SPSRM showed a yield around $81 \%$. The simulations were performed using nominal values of input voltage and load.

The experiments were performed at various points of operation where the increase in load forced the machine to slow down, increasing its power. This test showed that with the same dc bus voltage the TPSRM work with greater speed and requiring less power input. Furthermore, when subjected to the same load, the TPSRM needed less input power (4 times less).

So for all these factors it is concluded that the TPSRM when operated in the same way as was done here, and far more advantageous than SPSRM.

\section{Acknowledgement}

The authors thank the Federal University of Uberlandia and the PUC-GO, for multiple collaborations. And to CAPES for the scholarships.

\section{References}

[1] K.A, Joseph, “ Opportunities for switched reluctance motor-drives", Pulp and Paper Industry Technical Conference, 1999. Conference Record of 1999 Annual, 1999,pp.42-47.

[2] H. Chen, Y. Guo, " Green methodologies and technologies of switched reluctance motor drive.", Proceedings of the 3 World Congress on Intelligent Control and Automation, vol 5,2000, pp.3717-3720.

[3] L. Chang, "Switched Reluctance Motors: Small Motors of the Next Generations for Automobiles?", Vehicular Technology Conference, vol 5, 2003, pp.3316-3320.

[4] H. Chen, "Implementation of a Three-Phase Switched Reluctance Generator System for Wind Power Applications", Electromagnetic Launch Technology,2008 $14^{\text {th }}$ Symposium on, 2008, pp.1-6.K.

[5] C.Yookpakdee, N.H. Fuenqwarodsakul, "Variable Speed Switched Reluctance Drive for a Low Cost Applications", Electrical Engineering/Electronic, Computer, Telecommunications and Information Technology,2009, ECTI-CON,2009. ${ }^{\text {th }}$ International Conference on, vol 1, 2009, pp.262-265.

[6] S. Jose, E.S. Antonio, C. Maria Rosario, " Design of a system for analysis and monitoring of vibrations in Linear Switched Reluctance machines", MELECON 2010-2010 $15^{\text {th }}$ IEEE Mediterranean Electrotechnica Conference, 2010, pp.768-773.

[7] M.R. Harris, T.J.E. Miller, "Comparison of Design and Performance Parameters in Switched Reluctance and Induction Motors", Electrical Machines and Drives, 1989. Fourth International Conference on, 1989, pp.303-307.Y

[8] bKRISHNAN, Ramu, "Switched Reluctance Motors Drives.” CRC Press, 2001.

[9] S V. F, Augusto, "Modelagem, Construção, Testes e Analise de Desempenho de um Gerador à Relutância Chaveado", Tese de Doutorado, Universidade Federal de Uberlândia, Abril,2008. 